Bull. Egypt. Soc. Physiol. Sci. 40(2), 44-53

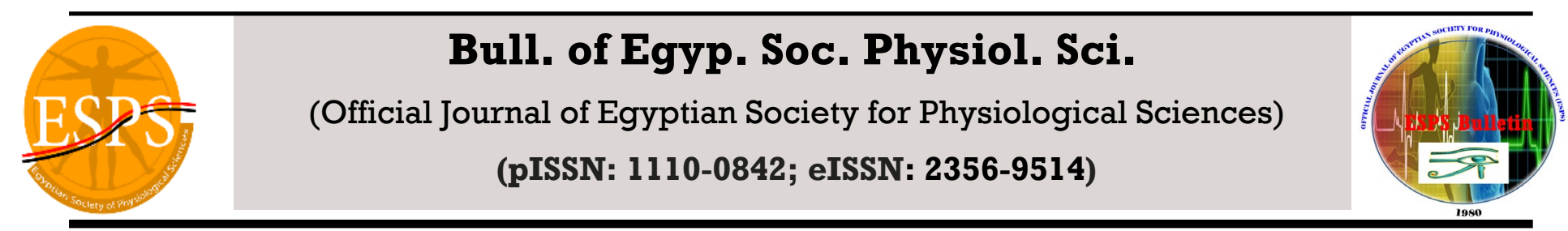

\title{
The Protective Effect Of L- Arginine and Ascorbic Acid on Dexamethasone
}

\section{Induced-Hypertension in Rats}

\author{
Mohamed Abdo*, Lobna Nagy, Magda Mohamed Ibraheim \\ Department of Medical Physiology, Faculty of Medicine, Suez Canal University, Ismailia, Egypt.
}

Received: 27 Dec, 2019 Accepted: $13 \mathrm{Feb} 2020$ Available online: 1 July 2020

\section{Keywords}

- Nitric oxide,

- Oxidative stress

- Vasodilatation

\begin{abstract}
Excess use of glucocorticoids either natural or synthetic has been associated with hypertension. Dexamethasone is a synthetic glucocorticoid with multiple uses. Recent studies demonstrated that dexamethasone induced hypertension is of endothelial dysfunction and decreased nitric oxide (NO) production. This work was designed to investigate the protective effect of L-arginine and ascorbic acid on dexamethasone induced hypertension in rats. Thirty adult male Albino rats were used in this study. Rats were equally divided into 5 groups: (G 1) Negative control group, (G 2): Positive hypertensive group, (G 3): L - arginine treated group, (G 4): Ascorbic acid treated group and (G 5): combined L-arginine and ascorbic acid treated group. L - arginine, ascorbic acid were given 2 weeks before induction of hypertension. Rats were followed up by measuring arterial blood pressure, Nitric oxide in urine and tissue homogenate, Total antioxidant capacity in serum and histopathology. Dexamethasone increased systolic $(260.16 \pm 28.9 \mathrm{mmHg})$ and diastolic blood pressure $(149.8 \pm 7.22 \mathrm{mmHg})$, decreased NO in tissue $(72.1 \pm 5.2 \mu \mathrm{mol} / \mathrm{g})$ and urine $(0.26 \pm 0.04 \mu \mathrm{mol} / 24 \mathrm{~h})$. Combination between L-arginine and ascorbic acid normalized systolic $(118.6 \pm 5.3 \mathrm{mmHg})$ and diastolic $(79.5 \pm 5.04 \mathrm{mmHg})$ blood pressure and increased NO in aortic tissue (135.5 $\pm 7.1 \mu \mathrm{mol} / \mathrm{g})$ and urine $(0.6 \pm 0.08 \mu \mathrm{mol} / 24 \mathrm{~h})$ denoting that combination between Larginine and ascorbic acid could effectively prevent dexamethasone induced hypertension.
\end{abstract}




\section{INTRODUCTION}

Hypertension is one of the leading risk factors for cardiovascular diseases. It is a cause of death in about more than 7 million individual every year. It is a leading risk factor for mortality and ranked as the third cause of disability-adjusted-life-years. (1) Dexamethasone is the most effective synthetic glucocorticoid. The potent anti-inflammatory and immunosuppressant properties of dexamethasone render it useful in various inflammatory and autoimmune diseases. $(2,3)$

Hypertension is a common manifestation of chronic dexamethasone use. The exact mechanism is unknown. There is accumulating evidence suggest that nitric oxide (NO) deficiency has a role in the development of dexamethasone induced hypertension. NO is formed from L-arginine. Induced deficiency of L-arginine in rats can produce hypertension and cause NO deficiency and this demonstrates the role of L-arginine to maintain NO level constant. $(4,5,6)$

It is also believed that one of the major reasons for dexamethasone-induced hypertension is the oxidative stress. Ascorbic acid is a potent scavenger of free radicals. It stimulates NO synthesis in endothelial cells and could contribute to improved endothelial-dependent vasodilation in hypertension (7).

\section{Materials and methods:}

\section{Animals:}

Thirty adult male Albino rats with average weight $250 \pm 50$ gm were used in this study

Study groups: Rats were equally divided into 5 groups:

Group 1 (G 1): Negative control group

Group 2 (G 2): Positive hypertensive group

Group 3 (G 3): L - arginine treated group
Group 4 (G 4): Ascorbic acid treated group

Group 5 (G 5): combined L-arginine and ascorbic acid treated group

Type of Study: An experimental study.

Study Site: This study was carried out in the Physiology department, faculty of medicine, Suez Canal University.

\section{Induction of hypertension in rats:}

Hypertension was induced by subcutaneous injection of dexamethasone at a dose of $20 \mu \mathrm{g} / \mathrm{kg}$ daily for 2 weeks (8) in groups 2, 3, 4 and 5 . Administration of $\mathrm{L}-$ arginine in G 3, Ascorbic acid in $\mathrm{G} 4$ and combination between them in G 5 was done 2 weeks before induction of hypertension

\section{Follow up:}

Rats were followed up by measuring:

1. Arterial blood pressure.

2. Nitric oxide in urine.

3. Nitric oxide in tissue homogenate.

4. Total antioxidant capacity in serum.

5. Histopathology.

\section{Blood Pressure assessment:}

Arterial blood pressure was measured in conscious rats by tail-cuff sphygmomanometer using BIOPAC system, MP150.

\section{Nitric oxide in urine:}

Rats were housed in metabolic cages for 24-hour urine collection for NO assay in urine.

\section{Nitric oxide in tissue homogenate:}

After sacrifice of rats, aorta was isolated, homogenized and centrifuged for NO assay.

\section{Total antioxidant capacity in serum:}

Blood samples were collected from orbital sinus and centrifuged to obtain serum for total antioxidant assay. 


\section{Histopathology:}

After scarification of the rats, the aorta was isolated and stained with hematoxylin and eosin dye for histopathological evaluation.

\section{Statistical analysis:}

All data was analyzed with SPSS. and presented as mean $\pm \mathrm{SD}$. ANOVA and post hoc tests were used. $\mathrm{P}$ value $<0.05$ was considered statistically significant.

\section{Results:}

\section{Blood pressure results:}

a) The effect of L - arginine, ascorbic acid and their combination on systolic blood pressure

Dexamethasone caused significant increase in systolic blood pressure in G2 $(260.16 \pm 28.9$ $\mathrm{mmHg})$ when compared to $\mathrm{G} 1(115 \pm 4.5 \mathrm{mmHg})$. There was significant decrease in systolic blood pressure in G 3 (170.8 $\pm 6.2 \mathrm{mmHg}), \mathrm{G} 4$ (143.6 \pm $4.1 \mathrm{mmHg})$ and $\mathrm{G} 5(118.6 \pm 5.3 \mathrm{mmHg})$ when compared to $\mathrm{G} 2(260.16 \pm 28.9 \mathrm{mmHg})$. There was significant difference between G 3 and G 1 (P $=0.000), \mathrm{G} 4(\mathrm{P}=0.016)$ and $\mathrm{G} 5(\mathrm{P}=0.000)$. Also there was significant difference between G 4 and $\mathrm{G} 1(\mathrm{P}=0.010) \& \mathrm{G} 5(\mathrm{P}=0.016)$ but there was no significant difference between $\mathrm{G} 1$ and G 5 $(\mathrm{P}=0.990)$ denoting that combination between Larginine and ascorbic acid normalized the systolic blood pressure (figure 1).

b) The effect of L - arginine, ascorbic acid and their combination on diastolic blood pressure:

Dexamethasone caused significant increase in diastolic blood pressure in $\mathrm{G} 2(149.8 \pm 7.22$ $\mathrm{mmHg})$ when compared to $\mathrm{G} 1(77.2 \pm 4 \mathrm{mmHg})$ there was significant decrease in diastolic blood pressure in G $3(117.6 \pm 6.28 \mathrm{mmHg}), \mathrm{G} 4$ (96.3 \pm $1.5 \mathrm{mmHg})$ and $\mathrm{G} 5(79.5 \pm 5.04 \mathrm{mmHg})$ when compared to G 2 (149.8 $\pm 7.22 \mathrm{mmHg})$. There was significant difference between G 3 and other treated groups ( $\mathrm{p}$ value is $0.000,0.000$ respectively) and between $G 3$ and the normal control group $(\mathrm{P}=0.000)$. Also, there was significant difference between $\mathrm{G} 4$ and $\mathrm{G} 1$ (P = $0.000)$ and $\mathrm{G} 5(\mathrm{P}=0.000)$ but there was no significant difference between $\mathrm{G} 1$ and G 5 (P = 0.935) denoting that combination between Larginine and ascorbic acid normalized the diastolic blood pressure (figure 2).

\section{2-Findings of nitric oxide in urine ( $\mu \mathrm{mol} / 24 \mathrm{~h})$ :}

Hypertensive rats had significant decrease in nitric oxide level in urine when compared to $\mathrm{G} 1(\mathrm{P}=$ 0.000), G 3(P =0.021), G $4(\mathrm{P}=0.008)$ and $\mathrm{G} 5$ (P $=0.000)$. There was statistically significant difference between $\mathrm{G} 5$ and groups $\mathrm{G} 3$ ( $\mathrm{P}=$ $0.015)$ and $\mathrm{G} 4(\mathrm{P}=0.040)$ but there was no statistically significant difference between G 3 and G $4(\mathrm{P}=0.993)$. Also there was statistically significant difference between $\mathrm{G} 1$ and $\mathrm{G} 3$ (P = $0.000)$ and $\mathrm{G} 4(\mathrm{P}=0.000)$ but there was no significant difference between $\mathrm{G} 1$ and $\mathrm{G} 5$ (P = 0.187) (figure $3 \mathrm{~A}$ ).

\section{3-Findings of nitric oxide assay in aortic tissue} homogenate ( $\mu \mathrm{mol} / \mathrm{g}$ tissue):

Hypertensive rats had significant decrease in nitric oxide level in aortic tissue when compared to $\mathrm{G} 1$ $(\mathrm{P}=0.000), \mathrm{G} 3(\mathrm{P}=0.003), \mathrm{G} 4(\mathrm{P}=0.000)$ and $\mathrm{G}$ $5(\mathrm{P}=0.000)$. Nitric oxide level in the aortic tissue was significantly decreased in G3 when compared with $\mathrm{G} 4(\mathrm{P}=0.000)$ and $\mathrm{G} 5(\mathrm{P}=0.000)$ and significantly increased in G5 when compared with $\mathrm{G} 4(\mathrm{P}=0.024)$. There was statistically significant difference between $\mathrm{G} 1$ and $\mathrm{G} 3(\mathrm{P}=0.000)$ and $\mathrm{G}$ $4(\mathrm{P}=0.015)$ but there was no significant difference between $\mathrm{G} 1$ and $\mathrm{G} 5$ ( $\mathrm{P}=1.00$ ) (figure $3 \mathrm{~B})$. 


\section{4-Total antioxidant capacity findings:}

Hypertensive rats had significant decrease in total antioxidant capacity when compared with $\mathrm{G} 1(\mathrm{P}=$ 0.000), G $3(P=0.007), G 4(P=0.000)$ and $G 5$ $(\mathrm{P}=0.000)$. Total antioxidant capacity was significantly decreased in $G 3$ when compared with $\mathrm{G} 4(\mathrm{P}=0.036)$ and $\mathrm{G} 5(\mathrm{P}=0.000)$ and significantly increased in G 5 when compared with $\mathrm{G} 4(\mathrm{P}=0.017)$. There was statistically significant difference between $\mathrm{G} 1$ and $\mathrm{G} 3(\mathrm{P}=0.036)$ but there was no significant difference between $G 1$ and $\mathrm{G} 5(\mathrm{P}=1.00)$ and $\mathrm{G} 4(\mathrm{P}=1.00)$ (figure $3 \mathrm{C})$.

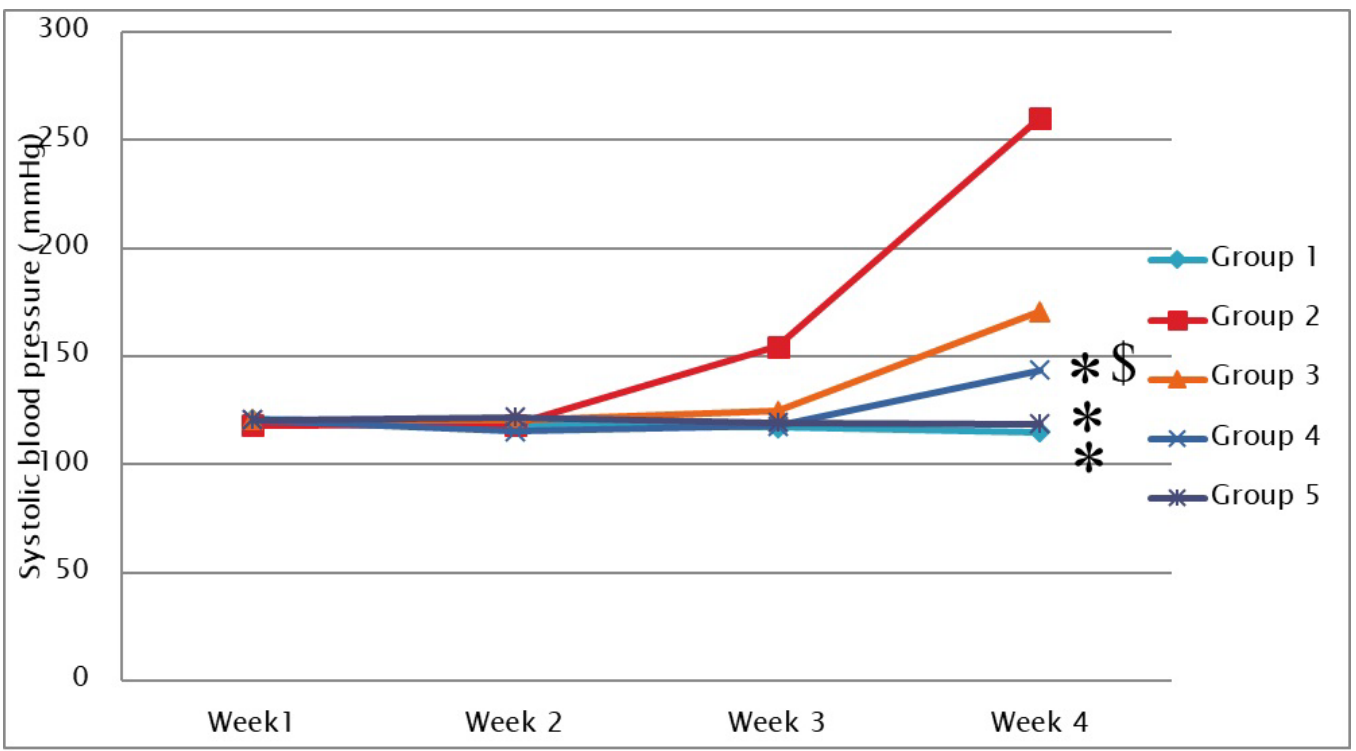

Figure 1: Pattern of systolic blood pressure in study groups through the study period. \$ Significant from G1, * Significant from $\mathrm{G} 2$

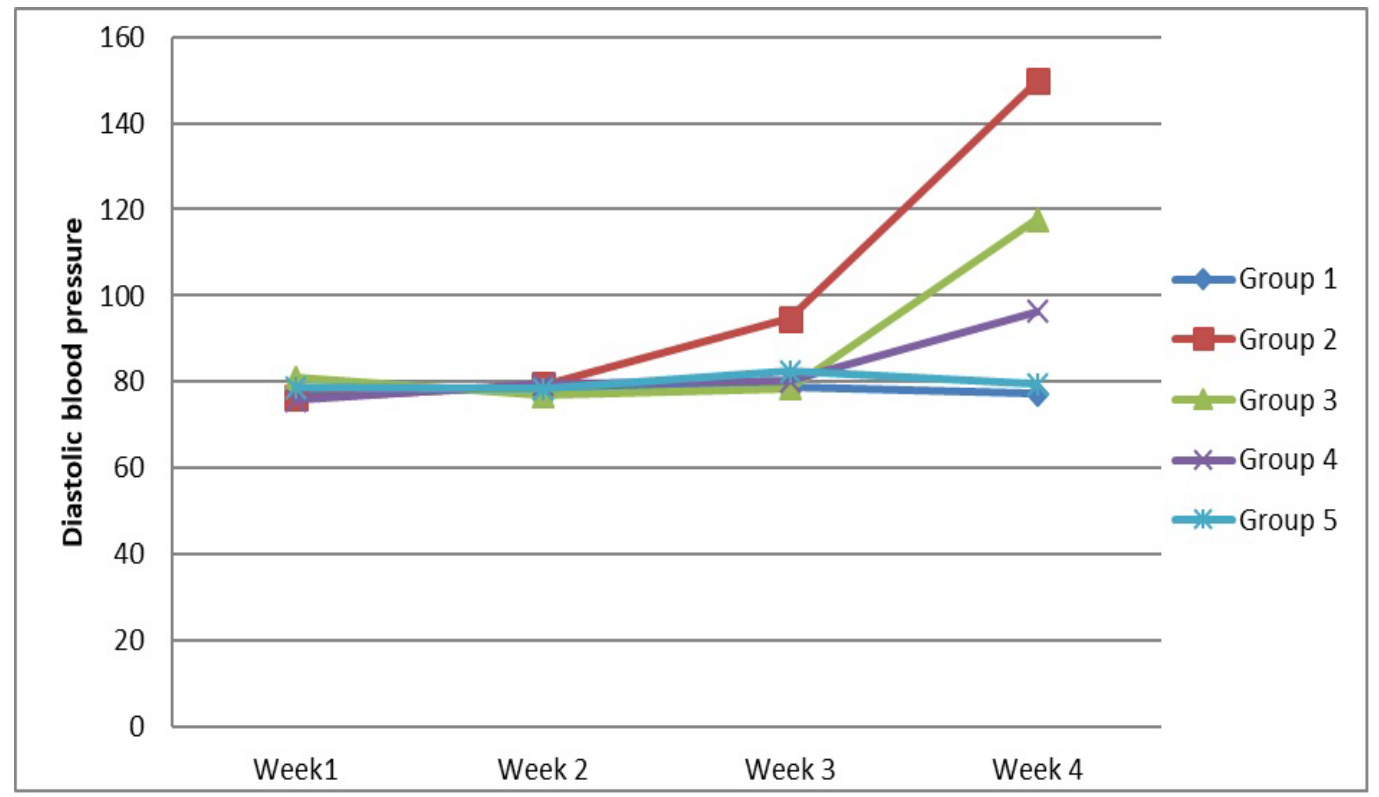

Figure 2: Pattern of diastolic blood pressure in study groups through the study period. \$ Significant from G1, * Significant from G2 

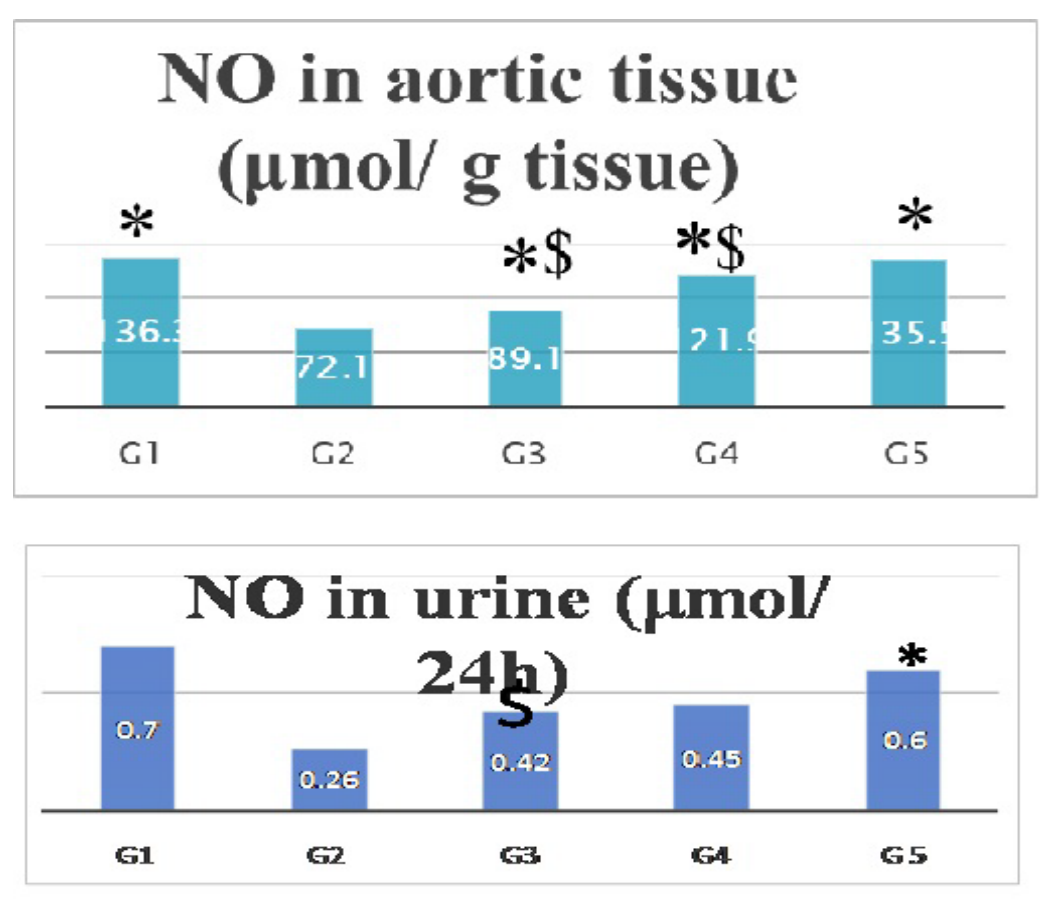

\section{Total antioxidant} capacity $(\mathrm{mM} / \mathrm{L})$
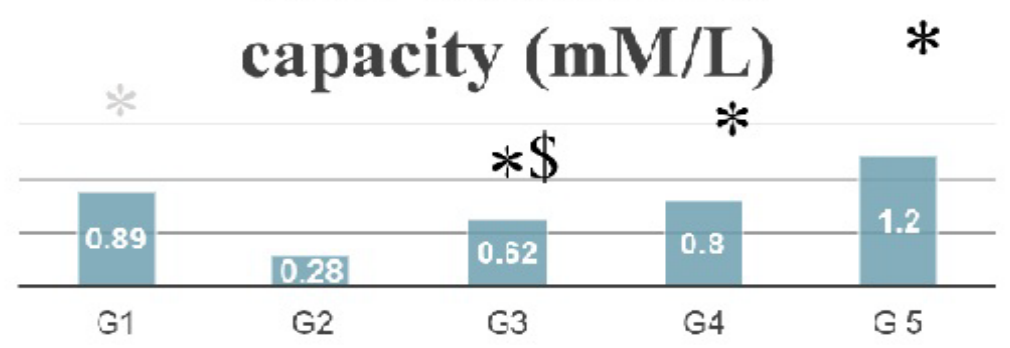

Figure (3): A. NO in urine, B. NO in aortic tissue and C. total antioxidant capacity in all the studied groups. * Significant from G2, \$ Significant from G1

\section{5- Histopathological results:}

Figure 4 showed the histopathological results in normal control group in which the blood vessel wall was normal with intact tunica intima and endothelial cells with regular tunica media showing parallel arrangement of elastic fibers with average thickness. Hypertensive group showed vessel wall with distorted tunica intima showing shed endothelial cells with thickened tunica media showing distortion of arrangement of elastic fibers with vacuolar degeneration of smooth muscle fibers (figure 4). L-arginine treated group showed vessel wall with residual distorted and shed endothelial cells with slightly thickened tunica media showing distortion of arrangement of elastic fibers (figure 5). Ascorbic acid treated group showed marked improvement of vessel wall showed focally restored endothelial lining of tunica intima with still notable shedding of few endothelial cells, well-formed parallel elastic fibers of tunica media with residual increase in medial thickness and no degeneration (figure 6). Combined L-arginine and ascorbic acid treated group showed marked improvement of vessel wall showed restored endothelial lining of tunica intima and well-formed parallel elastic fibers of tunica media with decrease thickness and no degeneration (figure 7). 


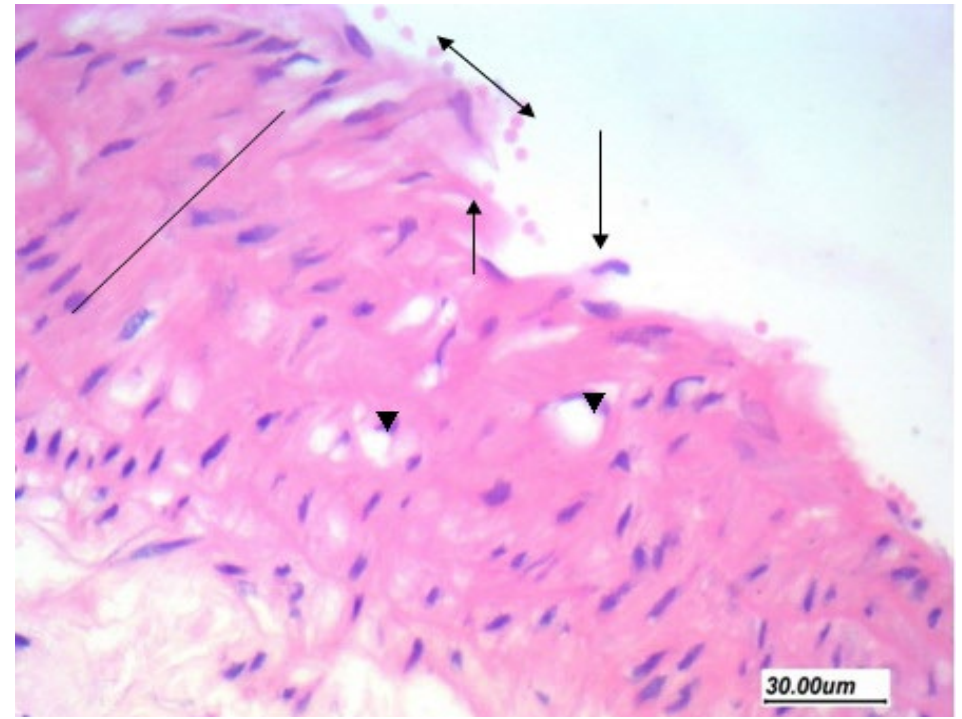

Figure 4: Aortic tissue in hypertensive group, $\mathbf{H}$ and $\mathbf{E}$ stain $(\mathbf{4 0} \mathbf{x})$ : showed distorted tunica intima $(\downarrow)$ with shed endothelial cells $(\leftrightarrow)$ and thickened tunica media showing distortion of arrangement of elastic fibers $(-)$ and vacuolar degeneration of smooth muscle fibers $(\boldsymbol{\nabla})$.

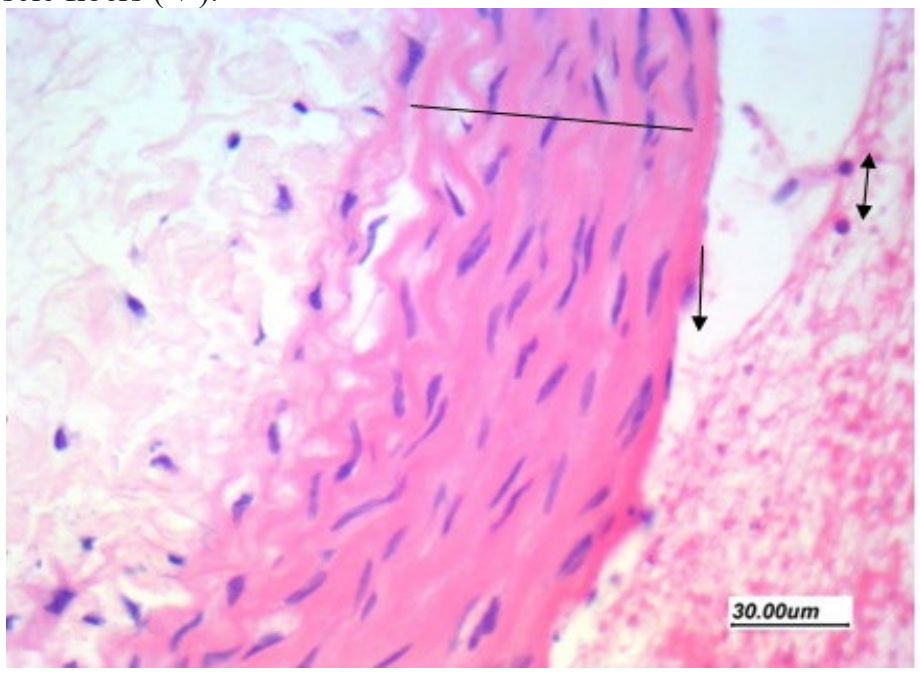

Figure 5: Aortic tissue in L- arginine treated group, $\mathbf{H}$ and $\mathbf{E}$ stain $(\mathbf{4 0} \mathbf{x})$ : showed vessel wall with residual distorted tunica intima $(\downarrow)$ and shed endothelial cells $(\leftrightarrow)$ with slightly thickened tunica media with distortion of arrangement of elastic fibers (一).

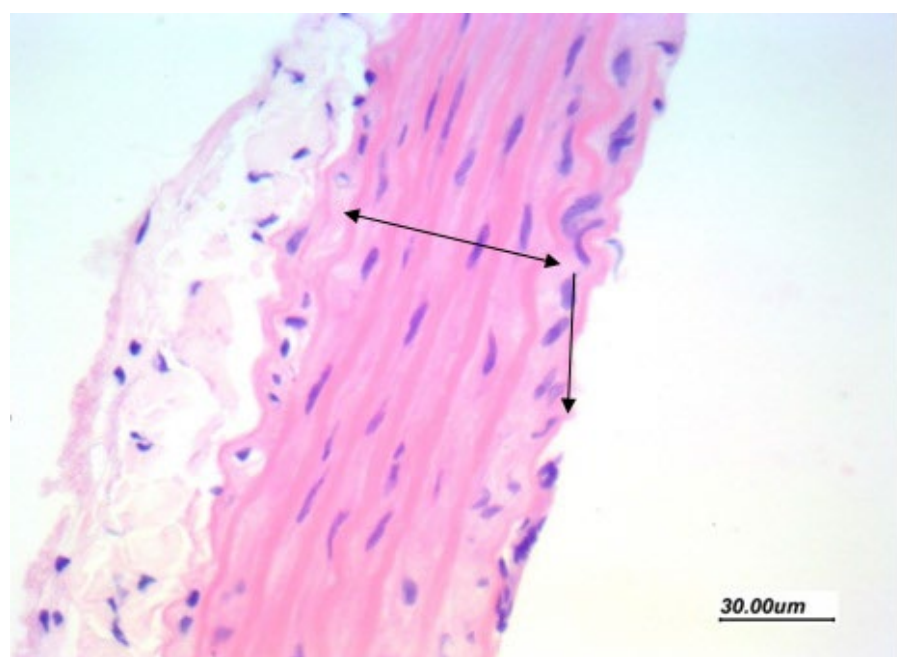

Figure 6: Aortic tissue in ascorbic acid treated group, $\mathbf{H}$ and $\mathbf{E}$ stain $(40 \mathrm{x})$ : showed marked improvement of vessel wall showed focally restored endothelial lining of tunica intima $(\downarrow)$ and well-formed parallel elastic fibers of tunica media $(\leftrightarrow)$ with residual increase in medial thickness and no degeneration. 


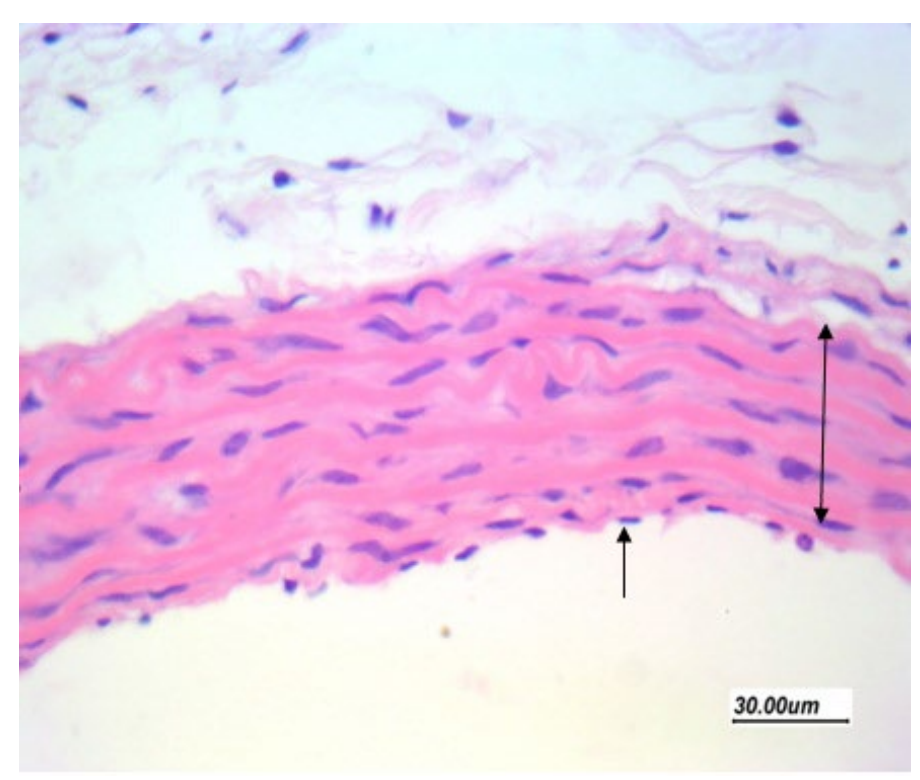

Figure 7: Aortic tissue in combined L- arginine and ascorbic acid treated group, $\mathbf{H}$ and $\mathbf{E}$ stain (40 $\mathbf{x})$ : showed marked improvement of vessel wall with restored endothelial lining of tunica intima $(\uparrow)$ and well-formed parallel elastic fibers of tunica media $(\uparrow)$ with decrease thickness and no degeneration.

\section{Discussion:}

The present study was designed to investigate the protective effect of L-arginine, ascorbic acid and combination between them in prevention of dexamethasone induced hypertension in rats. Administration of dexamethasone caused significant increase in systolic and diastolic blood pressure in G 2 when compared to control group. Administration of Larginine before hypertension induction significantly decreased both systolic and diastolic blood pressure when compared to $G$ 2. These findings are concordant to Schafer (2004) who demonstrated that L-arginine could reverse the effect of dexamethasone on microvascular arterioles suggesting usefulness of L-arginine in the treatment of glucocorticoid-induced hypertension (5). Ong et al., (2009) also demonstrated that dexamethasone induced hypertension is associated with a defect in the transport system of L-arginine in cardiac microvascular endothelial cells which leads to intracellular L-arginine deficiency so administration of L-arginine can stimulate the transport system and increase synthesis of $\mathrm{NO}(9)$.

Administration of ascorbic acid significantly decreased systolic and diastolic blood pressure. This finding was explained by the antioxidant property of ascorbic acid that can produce vasodilatation by prevention of oxidative stress thus increasing the level of NO. Many studies found that dexamethasone hypertensive rats had low level of antioxidant enzymes and antioxidants cause prevention and / or treatment of dexamethasone induced hypertension and this may explain the underlying cause of this finding (1013). In this study administration of L-arginine or ascorbic acid alone could decrease the blood pressure but not to the normal range, however combination between them could normalize the blood pressure. This may reflect that increased synthesis of NO and prevention of its oxidation by ROS could be used together for effective 
prevention of dexamethasone induced hypertension.

NO level in aortic tissue was significantly decreased in hypertensive rats when compared to control group. These results are similar to those found by Iuchi, (14) who reported decrease NO level by dexamethasone treatment in human umbilical vein endothelial cell culture. These data support a role for the NO in dexamethasoneinduced hypertension. Treatment with L- Arginine, Ascorbic acid, and combination of both of them significantly increased NO level in the aortic tissue. The beneficial effect of L-arginine and ascorbic acid may be explained by restoration and/or increase NO production by increased NO production and increased NO bioavailability thus reducing oxidative stress. And so combination between them gave better results than use each of them separately (8).

In this study dexamethasone treated rats showed significant decrease in total antioxidant capacity which is consistent with previous studies that showed dexamethasone hypertensive rats had a low levels of anti-oxidant enzymes and treatments with antioxidants such as tempol, apocynin, $\mathrm{N}$-acetylcysteine, folic acid and aspirin cause prevention and /or treatment of dexamethasone induced hypertension. This demonstrates the main role of oxidative stress in the pathogenesis of dexamethasone-induced hypertension (10-13).

Histopathological assessment revealed that dexamethasone caused distortion in tunica intima, shedding of endothelial cells with thickened tunica media showing distortion of arrangement of elastic fibers with vacuolar degeneration of smooth muscle fibers. Treatment with L-arginine caused mild improvement in vessel wall with residual distortion. These findings are in agreement with Schafer, (2004) who demonstrated that dexamethasone suppresses endothelium-dependent vasodilation of resistance arterioles in mice (5). This may be due to decrease NO synthesis on one side and increase formation of ROS on the other side which can lead to endothelial dysfunction, increased vascular tone, promotion of cellular growth and increased deposition of extracellular matrix protein $(15,16)$ and this may be the cause of these findings.

Treatment with ascorbic acid and combination between L-arginine and ascorbic acid resulted in marked improvement of vessel wall with This finding is in agreement with Chen et al., who demonstrated that ascorbic acid caused vasorelaxation, decreased media thickness and media to lumen ratio in superior mesenteric arteries in stroke-prone spontaneously hypertensive rats (17).

Combination between L-arginine and ascorbic acid also showed more improvement in histopathology than L-arginine but there was no marked difference in histopathology in combined treatment than ascorbic acid despite significant changes between them in other biochemical parameters studied. This might be due to the short period of administration which can correct the biochemical changes but histopathological changes may require a long period of administration to be corrected.

\section{Conclusion}

Dexamethasone induced hypertension in rats was associated with decreased nitric oxide in the aortic tissue, its metabolites in urine, decreased total antioxidant status and finally histopathological 
changes evident by distortion in tunica intima, thickening in tunica media with vacuolar degeneration.

L-arginine and ascorbic acid caused partial improvement in blood pressure, increased NO in the aortic tissue and its metabolites in urine, improvement of total antioxidant capacity and histopathology.

Ascorbic acid made more improvement than Larginine treated group in all the measured parameters which reflects the main role of oxidative stress in the pathogenesis of dexamethasone induced hypertension.

Combination between L-arginine and ascorbic acid could effectively prevent dexamethasone induced hypertension and it gave better results in restoration of $\mathrm{NO}$ and improvement of antioxidant status than use each of them separately and this reflects that decreased NO synthesis on one side and enhanced generation of ROS on the other side are main mechanisms in the pathogenesis of dexamethasone induced hypertension.

\section{References:}

1. Gupta, R. and Xavier, D. (2018). Hypertension: The most important non communicable disease risk factor in India. Indian Heart Journal, 70(4), pp.565-572.

2. Samuel, S., Nguyen, T. and Choi, H. (2017). Pharmacologic Characteristics of Corticosteroids. Journal of Neurocritical Care, 10(2), pp.53-59.

3. Petrillo, M., Bortner, C. and Cidlowski, J. (2016). Glucocorticoids: Inflammation and Immunity. The Hypothalamic-PituitaryAdrenal Axis in Health and Disease, pp.43-63.

4. Malkawi, A., Alzoubi, K., Jacob, M., Matic, G., Ali, A., Al Faraj, A., Almuhanna, F.,
Dasouki, M. and Abdel Rahman, A. (2018).

Metabolomics Based Profiling of

Dexamethasone Side Effects in Rats. Frontiers in Pharmacology, 9.

5. Li, H., Forstermann, U. And Xia, N. Nitric oxide synthesis in vascular physiology and pathophysiology. Endothelial signaling in development and disease, pp.381-397; 2015.

6. Williamson, P., Ong, S., Whitworth, J. And Kelly, J. The role of sustained release isosorbidemononitrate on corticosteroidinduced hypertension in healthy human subjects. J hum hypertens, 29(12), pp.737-743; 2015.

7. Lobo, V., Patil, A., Phatak, A. And Chandra, N. Free radicals, antioxidants and functional foods: impact on human health. Pharmacognosy reviews, 4(8), p.118; 2010.

8. Hu, L., Zhang, Y., Lim, P., Miao, Y., Tan, C., Mckenzie, K., Schyvens, C. And Whitworth, J. Apocynin but not l-arginine prevents and reverses dexamethasone-induced hypertension in the rat. American journal of hypertension, 19(4), pp.413-418; 2006.

9. Ong, S., Zhang, Y. And Whitworth, J. Mechanisms of dexamethasone-induced hypertension. Chyr, 5(1), pp.61-74; 2009.

10. Zhang, Y., Jang, R., Mori, T., Croft, K., Schyvens, C., Mckenzie, K. And Whitworth, J. The anti-oxidant tempol reverses and partially prevents adrenocorticotrophic hormone-induced hypertension in the rat. Journal of hypertension, 21(8), pp.1513-1518; 2004.

11. Miao, Y., Zhang, Y., Lim, P., Kanjanapan, Y., Mori, T., Croft, K., Earl, J., Lee, S., Mckenzie, K. And Hu, L. Folic acid prevents 
and partially reverses glucocorticoid-induced hypertension in the rat. American journal of hypertension, 20(3), pp.304-310; 2007.

12. Zhang Y, Miao Y, Whitworth Ja. Aspirin prevents and partially reverses adrenocorticotropic hormone-induced hypertension in the rat. Am $\mathrm{j}$ hypertens, 20, pp.1222-8; 2007.

13. Krug, S., Zhang, Y., Mori, T., Croft, K., Vickers, J., Langton, L. And Whitworth, J. $\mathrm{N}$-acetylcysteine prevents but does not reverse dexamethasone-induced hypertension. Clinical and experimental pharmacology and physiology, 35(8), pp.979-981; 2008.

14. Iuchi, T. Glucocorticoid excess induces superoxide production in vascular endothelial cells and elicits vascular endothelial dysfunction. Circulation research, 92(1), pp.81-87; 2002.
15. Touyz, R. And Schiffrin, E. Reactive oxygen species in vascular biology. Implications in hypertension. Histochemistry and cell biology,122(4), pp.339-352; 2004.

16. Harrison, D., Gongora, M., Guzik, T. And Widder, J. Oxidative stress and hypertension. Journal of the american society of hypertension, 1(1), pp.30-44; 2007.

17. Chen, X., Touyz, R., Park, J. And Schiffrin, E. Antioxidant effects of vitamins $\mathrm{c}$ and e are associated with altered activation of vascular nadph oxidase and superoxide dismutase in stroke-prone shr. Hypertension, 38(3), pp.606$611 ; 2001$. 